\title{
Optimal Placement of Renewable Energy based Distributed Generation Units using MCDM Technique
}

\author{
Manoj Kumar Bansal \\ Amity School of Business, \\ Amity University, Uttar Pradesh, Noida - 201303, India. \\ E-mail: bansalbansalmk@gmail.com \\ Pratibha Garg \\ Amity School of Business, \\ Amity University, Uttar Pradesh, Noida - 201303, India. \\ Corresponding author: pgarg1@ amity.edu \\ Neha Gupta \\ Amity School of Business, \\ Amity University, Uttar Pradesh, Noida - 201303, India. \\ E-mail: ngupta10@amity.edu \\ Mohini Agarwal \\ Amity School of Business, \\ Amity University, Uttar Pradesh, Noida - 201303, India. \\ E-mail: magarwal@amity.edu
}

(Received on April 14, 2021; Accepted on June 18, 2021)

\begin{abstract}
The distribution of electricity has become a challenge as there are losses associated with its distribution and transmission. In reducing such losses employment of Distributed Generation units in the transmission network can benefit greatly. Thus, the concern is on the optimal placement of Distributed Generation units that can provide maximum benefits and optimize several conflicting attributes. In this paper, the emphasis is laid on determining an optimal location for the placement of a Distributed Generation unit under conflicting attributes such as losses, real and reactive power, and voltages at different buses. For this purpose, the Technique for Order of Preference by Similarity to best Solution a MultiCriteria Decision-Making technique, and Fuzzy TOPSIS technique have been employed for determining the optimal placement of 10 MW Distributed Generation unit at the IEEE 20 Bus System. The results obtained can significantly benefit in reducing losses and greatly help in economical perspective as well.
\end{abstract}

Keywords- Decision making, Distributed generation, Electricity, Fuzzy TOPSIS, Multi-criteria decision making, TOPSIS.

\author{
Abbreviation \\ DG: Distributed Generation \\ KW: Kilowatt \\ MW: Megawatt \\ IEEE: Institute of Electrical and Electronics Engineers \\ MCDM: Multi-Criteria Decision Making \\ PV: Photovoltaic
}




\section{Introduction}

The consumption of power defined as 'the amount of electrical energy consumed per unit of time', has rapidly increased demand in all sectors around the world. The power generated at a power station is transmitted to the load center and distributed to the consumers through high voltage transmission lines. During transmission, some power is lost to the surroundings because of the transmission medium's inherent properties, resulting in reducing the quantity of power available to consumers. The transformation from centralized power generation to distributed power generation is employed for reducing the electric power losses and satisfy the rapid growth of power demand. The conventional power plants are outdated as power generation is centralized, which supplies massive electricity from high-capacity long transmission lines. DG is categorized as conventional and renewable energy resources is an evolving technology associated with the distribution network for serving the local load.

DG units are associated either with the radial distribution network or to the customer side of the meter (Muthukumar and Jayalalitha, 2016). DG has played a significant role to reduce transmission and distribution losses. These are small capacity generators located at or near the electric load center range from a few KWs to MWs. DGs can be defined based on several criteria's which are shown in Figure 1 and can also be categorized as renewable energy-based, non-renewable energy, and energy storage. There are numerous DG technologies based on non-renewable energy resources such as petroleum, natural gas, coal, etc. For sustainable development, renewable energy sources like wind, solar, hydrokinetic energy, etc. based on DG technologies instilled in the utility distribution system have experienced huge demand. Installation of DG units has many benefits which include the following:

(i) Improved reliability.

(ii) Power quality.

(iii) Voltage stability.

(iv) Reduction of power losses.

(v) Flexibility in terms of cost and time.

(vi) Backup power.

(vii) Sustainable energy organization.

The introduction of DG systems is a challenging task as it changes the features of the distribution network from the traditional unidirectional power flow distribution system to bi-directional power flow. A high voltage problem can arise at a high penetration level because of the reversed flow of power, so the significant problem related to the installation of DG units in the distribution networks is to understand the optimum size and location for the stable, reliable, and efficient operation. Normally, the DG unit can be located at any node in the distribution network, but for loss reduction and voltage stability, the DG unit's optimum location plays a significant role. For this purpose, various optimization tools that exist in literature like the mathematical programming technique and multi-criteria decision-making tools like Artificial Bee Colony method, Genetic Algorithm, Differential Evaluation, and many more have been successfully employed by the researchers to study find the optimal location of DG, maximize the revenues generation (Gupta et al., 2021) with the use of renewable energy, minimize the loses or maximize the voltage for the power systems. Although these tools and techniques are widely used and provide an optimal solution, these algorithms are complex and require detailed knowledge of programming which sometimes becomes cumbersome. 


\section{DG Classification}

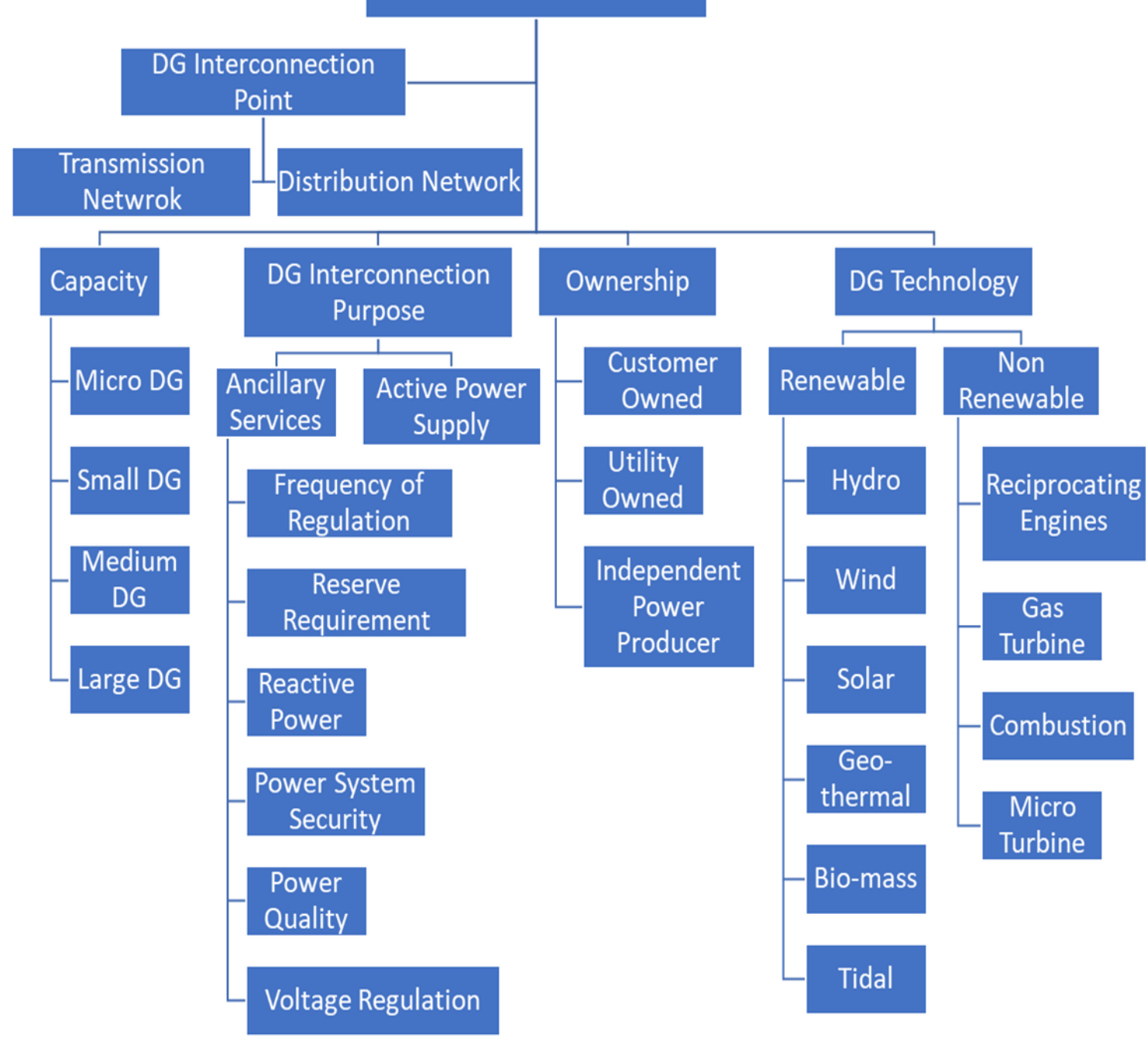

Figure 1. Classification of DGs.

In this study, the TOPSIS technique has been used for the identification of optimal placement of DG units at various buses to achieve the desired objectives. In the real scenario, the data or information we have for the criteria does not need to be deterministic usually they are imprecise therefore have we have extended the TOPSIS method to incorporate the vagueness in terms of fuzzy data. The research methodology has been pictorially summarised in Figure 2. In this paper, triangular fuzzy numbers have been utilized to rate alternatives and the weight of each criterion. Here for the optimum location of a renewable energy-based DG unit based on multiple criteria such as line losses, real and reactive power, and voltage stability. 


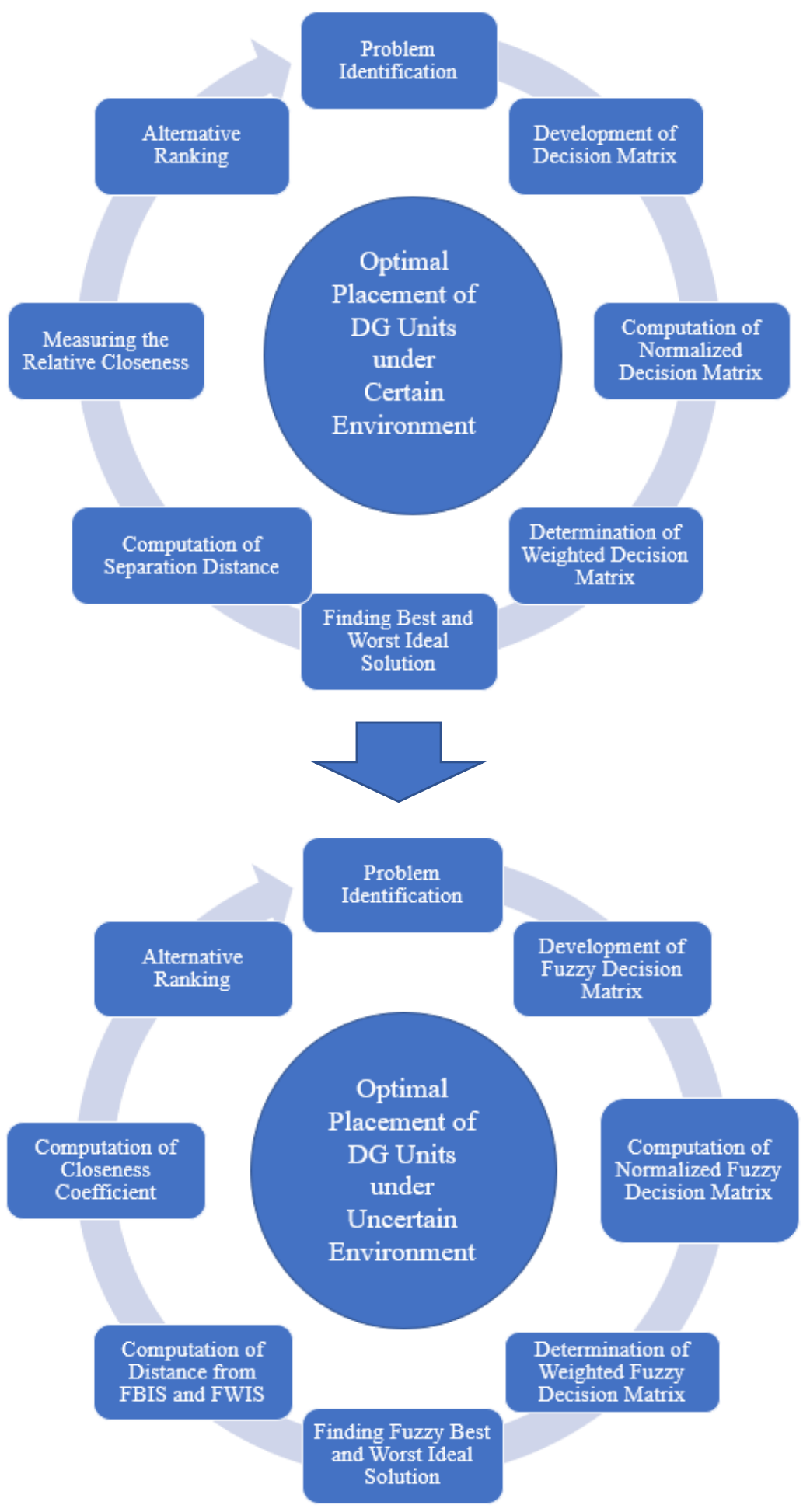

Figure 2. Research framework for identification of DG location. 
This paper is chronologically arranged as section 2 contains theoretical background wherein the literature about the DG and multi-criteria decision-making techniques have been conferred followed by problem, method, and analysis in section 3 followed Conclusion and future implications have been discussed in section 4 and lastly the list of references.

\section{Theoretical Background 2.1 Distributed Generation}

The technological advancements in electric utility structures have formed many prospects for systems improvement, involving DG. The employment of DG has significantly benefitted in terms of reducing losses and maximizing the system's efficiency. Barker and De Mello (2000) has defined a few issues that should be intended to ensure that DG will not lower distribution system power quality, safety, or reliability. They concentrated on radial systems, though some issues conferred are general to low voltage distribution networks. Dugan et al. (2001), suggested that traditional feeders and substations can be integrated with DGs as a part of distribution planning. Since the utilities are more capable of handling risk, rather than inflexible development and capacity systems, the present requirement shifts to comprehensive simulation for restrictions on capacity and failure cost at the customer end. Dugan and Mcdermott (2002) focus has been on distributed generators wherein authors have claimed that distributed generators are linked in the utility distribution system, which is generally smaller than 10MW. Chiradeja and Ramakumar (2004), highlighted the technical gains with the placement of DG in a quantitative manner. They worked on the 12-bus system to depict the usefulness of the developed indices of voltage reduction index, line loss reduction index, and DG performance index.

El-Khattam and Salama (2004) focused on a comprehensive survey of DGs and different types and operating technologies. Also, the operational and economic benefits of executing DGs in the distributed network were examined. Pepermans et al. (2005) projected the importance of smallscale electricity generation wherein the work began with surveying the existing technologies on a small scale. They highlighted the benefits and problems associated with small-scale electricity generation termed DG. Ramesh et al. (2007) worked on the structure of the distribution system to reduce active losses and balance the system load. The ideology is to minimize the losses, which will make the system more economical and efficiency conscious.

Campoccia et al. (2008) recommended the formulation and optimal solution method for best sizing and location problem of DG units grounded on PV. The problem was resolved using Non dominated sorting Genetic Algorithm II, NSGA-II, recognizing the best size and position of PV systems in diverse incentive strategies followed by both utility and national government. As the multi-objective approach has been exercised, the sizing and siting of PV units and the economic backing from the local electric utility permitting more significant advantages both for the utility company and the customers have been found. Guerrero et al. (2010) discussed DG, evolving as an innovative factor to generate extremely trustworthy and quality electrical power. This concept is predominantly fascinating when diverse energy resources are accessible, for instance, PV panels, wind turbines, fuel cells (FCs), etc.

In the work by Muthukumar and Jayalalitha (2016), an attempt has been made to lessen losses in distribution systems. It enables an augmentation in voltage profile by understanding the optimal size and location of DG units and shunt capacitors using the hybrid Harmony Search Algorithm method. Razavi et al. (2019) reviewed the function of DG in electrical grids from a technical point of view. They referred to the voltage regulation approaches in DG units' existence and their effect 
on protection systems. Malik et al. (2020) proposed the optimal incorporation of a wind turbine, solar photovoltaic DG beside biomass, and capacitor banks applying a multi-objective particle swarm optimization technique to optimize distribution network factors. They have been used to optimize the distribution network factors.

\subsection{Multi-Criteria Decision-Making Techniques}

Seeing the abundance of exploration in DG implementation and associated benefits, several researchers have focused on reducing the losses and balancing the load in the distributed network. Here, the focus is on the determination of optimal DG placement with the help of MCDM techniques. It agrees on assessing possibilities against varied choices considering several performance measures and a range of objectives (Mills et al., 1996). Linares and Romero (2000) anticipated a procedure that associates numerous multi-criteria methods to report electricity arrangement difficulties in a genuine context. The technique is employed for electricity arrangements in Spain with a planning horizon of 2030.

Pohekar and Ramachandran (2004) compiled around 90 published research papers to supplement the review and analyzed the applicability of several MCDM techniques in sustainable energy management. It was detected that the Analytical Hierarchy Process being the utmost common technique trailed by outranking techniques ELECTRE and PROMETHEE. In 2010, Li (2010) developed a nonlinear programming methodology by utilizing the concepts of the relativecloseness coefficient and the weighted-Euclidean distance to determine the ranking order of the alternatives.

In 2016, Chaube and Singh (2016) utilized fuzzy membership functions for evaluating systems' reliability and depicted the importance of fuzzy theory. Šarić et al. (2017) presented a procedure for DG provision planning, employing fuzzy set theory and MCDM grounded on the BellmanZadeh method. The anticipated model deliberates power losses and costs reduction values as objectives and line currents, node voltages, and short circuit power values as limitations. They aimed to generate a model used to offer the finest trade-offs between incompatible objectives and limitations; integrally exist in the DG provision problem. In 2018, Ren and Dong (2018) developed an MCDM approach for power supply sustainability and protection assessment. They have used the Fuzzy Analytic Hierarchy Process (FAHP) that permits the respondents to utilize linguistic terms to state their views, followed by Grey Rational Analysis for prioritizing the position of power supply sustainability and protection in few countries. Decision-making in an uncertain environment is the need of the hour (Saikia et al., 2020). Here both certain and uncertain environmental conditions have been used for decision making. In this paper, TOPSIS and Fuzzy TOPSIS techniques have been used for optimal positioning of DG.

\section{Problem and Method}

\subsection{Problem Formulation}

DG units can reduce line losses and provide environmental benefits. But the problem is to decide the finest position for the placement of DG units that provides the optimal results. The problem of the optimal position of DG units is formulated using alternatives and criteria. The alternatives, in this case, are potential buses on which DG units can be connected. There is a sizing limitation of DG. With the increase in size, the power losses decrease, but the power loss increases with the increase in the KW of the DG set after a certain limit. Therefore, a 10 MW DG unit has been selected as an optimal sizing. In this paper, a case study of Noida has been discussed, and the details of the distribution feeder are given in Table 1. Analysis has been done, how $10 \mathrm{MW}$ induction of 
DG help to reduce line losses. For 10 MW DG, IEEE 20 Bus system is used this is according to the need of the location, so $\mathrm{n}$ buses within the considered IEEE Bus System are involved in the probable alternatives vector $A_{j}=\left(A_{1}, A_{2}, \cdots, A_{n}\right)$. Several criteria, such as losses, real power, reactive power, voltage, cost of installation, etc., can be used in investigating a distribution network. Here the focus is on four criteria: losses $\left(C_{1}\right)$, real power $\left(C_{2}\right)$, reactive power $\left(C_{3}\right)$, and voltage $\left(C_{4}\right)$.

Table 1. Details of the NMRC distribution feeder.

\begin{tabular}{|l|c|}
\hline Substation Transformer & $132 / 33 \mathrm{kV}$ \\
\hline Total number of feeder buses & 20 \\
\hline Number of feeder Load buses & 10 \\
\hline Peak Load & $10 \mathrm{MW}$ \\
\hline Transformers in the Feeder & $650 \mathrm{KVA}$ \\
\hline
\end{tabular}

(Source: https://www.upenergy.in/)

The reduction in power loss due to DG shall be evaluated based on Electrical Transient Analysis Program (ETAP). This software is widely used in the transmission and distribution network to study load flow analysis. The values of all criteria are observed by linking one DG unit at different buses (alternatives). The values of criteria are estimated with simulations implemented in ATP for six looped networks. In the subsequent section, the steps of the TOPSIS technique have been discussed in detail.

\subsection{Technique for Order of Preference by Similarity to Ideal Solution}

Hwang and Yoon in (1981) developed a multi-criteria decision-making analysis technique that is the Technique for Order of Preference by Similarity to Ideal Solution (TOPSIS). This method is employed to determine the preference weights of the alternatives. Several steps must be executed to perform the TOPSIS technique, which is as follows:

Step 1: Prepare the decision matrix of order $m \times n$, where rows present the alternatives, and in columns, evaluation criteria are given which are used in decision-making:

$$
X_{i j}=\left[\begin{array}{ccc}
x_{11} & \cdots & x_{1 n} \\
\vdots & x_{i j} & \vdots \\
x_{m 1} & \cdots & x_{m n}
\end{array}\right], i=1,2, \ldots, m ; j=1,2, \ldots, n .
$$

In Table 2, the simulation outcomes are put together in the form of a decision matrix $X_{i j}$, where $i$ is an index for ' $\mathrm{m}$ ' likely alternatives and $j$ is the index for $\mathrm{n}$ criteria. Voltage is a beneficial criterion, which means a higher value is more attractive, while losses, real power, and reactive power are non-beneficial criteria.

Table 2. Decision matrix (certain environment).

\begin{tabular}{|c|c|c|c|c|}
\hline & Non-Beneficial & Non- Beneficial & Non- Beneficial & Beneficial \\
\hline Weightage & 0.25 & 0.15 & 0.15 & 0.45 \\
\hline Bus Number & $\boldsymbol{C}_{\mathbf{1}}$ & $\boldsymbol{C}_{\mathbf{2}}$ & $\boldsymbol{C}_{\mathbf{3}}$ & $\boldsymbol{C}_{\mathbf{4}}$ \\
\hline $\mathbf{0}$ & 12 & 28 & 15 & 0.95 \\
\hline $\mathbf{5}$ & 11.9 & 23 & 12 & 0.95 \\
\hline $\mathbf{1 0}$ & 11.5 & 35 & 20 & 0.94 \\
\hline $\mathbf{1 5}$ & 4 & 4.5 & 6 & 0.94 \\
\hline $\mathbf{2 0}$ & 8.9 & 7 & 4.5 & 0.97 \\
\hline
\end{tabular}


Step 2: Compute the normalized decision matrix, which signifies the relative performance of produced model alternatives.

$Z_{i j}=\frac{x_{i j}}{\sqrt{\sum_{i=1}^{m} x_{i j}^{2}}}$

Using the formula given in step 2 of the TOPSIS technique, the decision matrix is normalized and presented in Table 3.

Table 3. Normalized decision matrix.

\begin{tabular}{|c|c|c|c|c|}
\hline Bus Number & $\boldsymbol{C}_{\mathbf{1}}$ & $\boldsymbol{C}_{\mathbf{2}}$ & $\boldsymbol{C}_{\mathbf{3}}$ & $\boldsymbol{C}_{\mathbf{4}}$ \\
\hline $\mathbf{0}$ & 0.529777 & 0.548361169 & 0.52215386 & 0.447 \\
\hline $\mathbf{5}$ & 0.525362 & 0.450439531 & 0.417723088 & 0.447 \\
\hline $\mathbf{1 0}$ & 0.507703 & 0.685451461 & 0.696205146 & 0.442 \\
\hline $\mathbf{1 5}$ & 0.176592 & 0.088129474 & 0.208861544 & 0.442 \\
\hline $\mathbf{2 0}$ & 0.392918 & 0.137090292 & 0.156646158 & 0.457 \\
\hline
\end{tabular}

Step 3: Determine the weighted decision matrix by multiplying each element of each column of the normalized decision matrix by the weights $w_{j}$.

$\delta=\delta_{i j}=w_{j} \times R_{i j}$

Step 4: Find the best and worst ideal solution via equations below:

$$
\begin{aligned}
& A^{+}=\left\{\delta_{1}^{+}, \delta_{2}^{+}, \ldots, \delta_{n}^{+}\right\}, \text {where } \delta_{j}^{+}=\begin{array}{l}
\left\{\max \delta_{i j}, \text { if } j \in J\right\} \\
\left\{\min \delta_{i j}, \text { if } j \in J^{\prime}\right\}
\end{array} \\
& A^{-}=\left\{\delta_{1}^{-}, \delta_{2}^{-}, \ldots, \delta_{n}^{-}\right\}, \text {where } \delta_{j}^{-}=\begin{array}{l}
\left\{\min \delta_{i j}, \text { if } j \in J\right\} \\
\left\{\max \delta_{i j}, \text { if } j \in J^{\prime}\right\}
\end{array}
\end{aligned}
$$

where, $\mathrm{J}$ is allied with valuable attributes, and $\mathrm{J}^{\prime}$ is associated with the non-beneficial attributes.

Step 5: Compute the separation distance of each alternative from the ideal and non-ideal solutions.

$D^{+}=\sqrt{\sum_{j=1}^{n}\left(\delta_{j}^{+}-\delta_{i j}\right)^{2}}$

$D^{-}=\sqrt{\sum_{j=1}^{n}\left(\delta_{j}^{-}-\delta_{i j}\right)^{2}}$

Step 6: Measure the relative closeness of each location to the ideal solution using the formula given as:

$\vartheta_{i}=\frac{D_{i}^{-}}{\left(D_{i}^{+}+D_{i}^{-}\right)} ; \quad 0 \leq C_{i} \leq 1$

Step 7: Rank the preference order based on the value of $\vartheta_{i}$. The ranking order for a higher value of the relative closeness will be higher and, hence, the alternative's better performance. Then, after executing step 3 to step 7, the DG unit's optimal placement has been determined by evaluating DG units' performance at each bus. The results are summarised in Tables 4, 5, \& 6 . 
Table 4. Weighted decision matrix.

\begin{tabular}{|c|c|c|c|c|}
\hline Bus Number & $\boldsymbol{C}_{\mathbf{1}}$ & $\boldsymbol{C}_{\mathbf{2}}$ & $\boldsymbol{C}_{\mathbf{3}}$ & $\boldsymbol{C}_{\mathbf{4}}$ \\
\hline $\mathbf{0}$ & 0.132444 & 0.082254175 & 0.078323079 & 0.201 \\
\hline $\mathbf{5}$ & 0.13134 & 0.06756593 & 0.062658463 & 0.201 \\
\hline $\mathbf{1 0}$ & 0.126926 & 0.102817719 & 0.104430772 & 0.199 \\
\hline $\mathbf{1 5}$ & 0.044148 & 0.013219421 & 0.031329232 & 0.199 \\
\hline $\mathbf{2 0}$ & 0.098229 & 0.020563544 & 0.023496924 & 0.205 \\
\hline
\end{tabular}

Table 5. Best and worst ideal solution.

\begin{tabular}{|l|l|l|l|l|}
\hline $\boldsymbol{\delta}_{\boldsymbol{j}}^{+}$ & 0.044148 & 0.013219421 & 0.023496924 & 0.205 \\
\hline $\boldsymbol{\delta}_{\boldsymbol{j}}^{-}$ & 0.132444 & 0.102817719 & 0.104430772 & 0.199 \\
\hline
\end{tabular}

Table 6. Separation distance, relative closeness \& rank.

\begin{tabular}{|c|c|c|c|c|}
\hline Bus Number & $\boldsymbol{D}_{\boldsymbol{i}}^{-}$ & $\boldsymbol{D}_{\boldsymbol{i}}^{-}$ & $\boldsymbol{\vartheta}_{\boldsymbol{i}}$ & Rank \\
\hline $\mathbf{0}$ & 0.125 & 0.033 & 0.211 & 4 \\
\hline $\mathbf{5}$ & 0.11 & 0.055 & 0.332 & 3 \\
\hline $\mathbf{1 0}$ & 0.147 & 0.006 & 0.036 & 5 \\
\hline $\mathbf{1 5}$ & 0.01 & 0.145 & 0.935 & 1 \\
\hline $\mathbf{2 0}$ & 0.055 & 0.121 & 0.688 & 2 \\
\hline
\end{tabular}

Table 6 shows that if the DG unit is placed at the $15^{\text {th }}$ bus, then losses, real power, and reactive power are minimum, whereas voltage is maximum. Therefore, in IEEE 20 bus system $15^{\text {th }}$ bus is the optimal node to place the DG unit in the Noida region followed by the $20^{\text {th }}, 5^{\text {th }}, 0^{\text {th }}$, and $10^{\text {th }}$ bus (as shown in Figure 3).

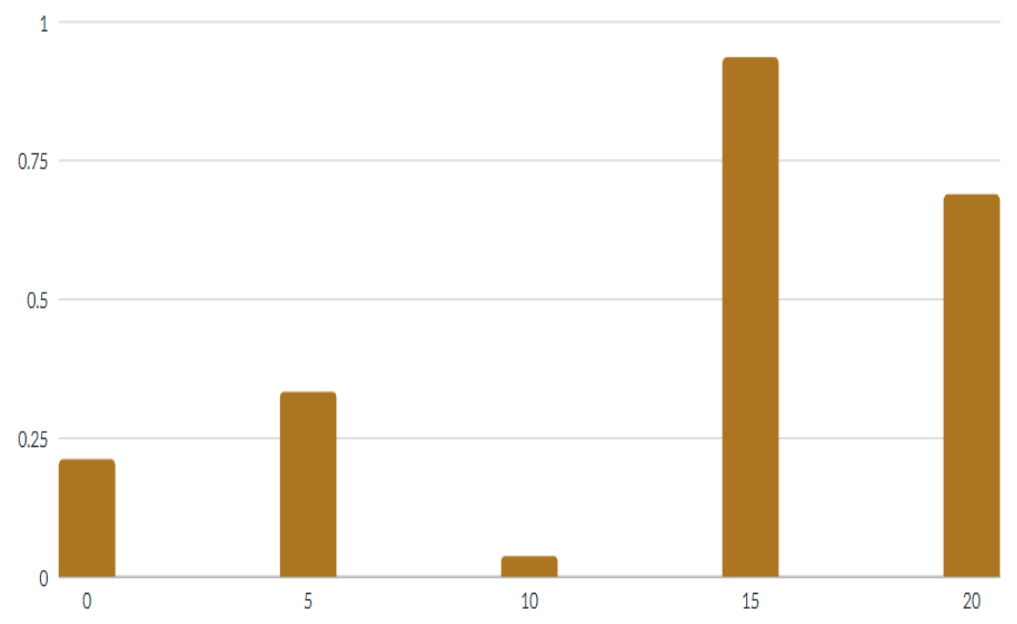

Figure 3. Closeness coefficient graph using TOPSIS.

\subsection{Fuzzy Technique for Order of Preference by Similarity to Ideal Solution} The stepwise approach of the Fuzzy TOPSIS method is explained below. 
Step 1: Decision Matrix Preparation

In this study, fuzzy TOPSIS is used to rank the 5 alternatives based on 4 criteria. Table 7 shows the type of criterion and fuzzy weight allocated to every criterion.

Table 7. Characteristics of criteria.

\begin{tabular}{|c|c|c|}
\hline Criteria & Type & Fuzzy Weight \\
\hline Loss & - & $(1,1,3)$ \\
\hline Real Power & - & $(1,3,5)$ \\
\hline Reactive Power & - & $(1,3,5)$ \\
\hline Voltage & + & $(5,7,9)$ \\
\hline
\end{tabular}

Table 8 shows the fuzzy scale used in the problem for weight determination.

Table 8. Fuzzy scale.

\begin{tabular}{|c|c|c|c|c|}
\hline Code & Qualitative Terms & Low & Medium & High \\
\hline 1 & Very low & 1 & 1 & 3 \\
\hline 2 & Low & 1 & 3 & 5 \\
\hline 3 & Medium & 3 & 5 & 7 \\
\hline 4 & High & 5 & 7 & 9 \\
\hline 5 & Very high & 7 & 9 & 9 \\
\hline
\end{tabular}

The fuzzy values for the alternatives in terms of several criteria are calculated by conducting the simulation three times at a particular bus number and the findings of the decision matrix are exhibited in Table 9.

Table 9. Decision matrix (uncertain environment).

\begin{tabular}{|c|c|c|c|c|c|c|c|c|c|c|c|c|c|}
\hline Weights & 1 & 1 & 3 & 1 & 3 & 5 & 1 & 3 & 5 & 5 & 7 & 9 \\
\hline Bus Number & \multicolumn{4}{|c|}{ Loss } & \multicolumn{3}{|c|}{ Real Power } & \multicolumn{3}{|c|}{ Reactive Power } & \multicolumn{3}{c|}{ Voltage } \\
\hline $\mathbf{0}$ & 10 & 10.5 & 12 & 24 & 26 & 28 & 11 & 13 & 15 & 0.7 & 0.85 & 0.95 \\
\hline $\mathbf{5}$ & 9 & 11.9 & 13 & 18 & 20 & 23 & 9 & 11 & 12 & 0.7 & 0.85 & 0.95 \\
\hline $\mathbf{1 0}$ & 9 & 11.5 & 12 & 30 & 32 & 35 & 17 & 18.5 & 20 & 0.64 & 0.8 & 0.94 \\
\hline $\mathbf{1 5}$ & 1 & 3 & 4 & 3 & 4.5 & 6 & 2 & 4 & 6 & 0.7 & 0.84 & 0.94 \\
\hline $\mathbf{2 0}$ & 7 & 8.9 & 10 & 4 & 5 & 7 & 2 & 4.5 & 6 & 0.72 & 0.85 & 0.97 \\
\hline
\end{tabular}

\section{Step 2: Develop the Normalized and Standardized Decision Matrix}

Normalized and standardized fuzzy decision matrix has been developed based on the best and worst ideal solutions by using the following formula:

$$
\begin{gathered}
\tilde{r}_{i j}=\left(\frac{a_{i j}}{c_{j}^{*}}, \frac{b_{i j}}{c_{j}^{*}}, \frac{c_{i j}}{c_{j}^{*}}\right) \quad ; c_{j}^{*}=\max _{i} c_{i j} \text {; Best ideal solution } \\
\tilde{r}_{i j}=\left(\frac{a_{j}^{-}}{c_{i j}}, \frac{a_{j}^{-}}{b_{i j}}, \frac{a_{j}^{-}}{a_{i j}}\right) \quad ; a_{j}^{-}=\min _{i} a_{i j} \text {; Worst ideal solution }
\end{gathered}
$$

The normalized decision matrix is shown in Table 10. 
Table 10. Normalized fuzzy decision matrix.

\begin{tabular}{|c|c|c|c|c|c|c|c|c|c|c|c|c|}
\hline Weights & 1 & 1 & 3 & 1 & 3 & 5 & 1 & 3 & 5 & 5 & 7 & 9 \\
\hline $\begin{array}{c}\text { Bus } \\
\text { Number }\end{array}$ & \multicolumn{3}{|c|}{ Loss } & \multicolumn{3}{|c|}{ Real Power } & \multicolumn{3}{|c|}{ Reactive Power } & \multicolumn{3}{|c|}{ Voltage } \\
\hline $\mathbf{0}$ & $\begin{array}{c}0.08 \\
3\end{array}$ & $\begin{array}{c}0.09 \\
5\end{array}$ & $\begin{array}{c}0.10 \\
0\end{array}$ & $\begin{array}{c}0.10 \\
7\end{array}$ & $\begin{array}{c}0.11 \\
5\end{array}$ & $\begin{array}{c}0.12 \\
5\end{array}$ & $\begin{array}{c}0.13 \\
3\end{array}$ & $\begin{array}{c}0.15 \\
4\end{array}$ & $\begin{array}{c}0.18 \\
2\end{array}$ & $\begin{array}{c}0.72164 \\
9\end{array}$ & 0.87628866 & $\begin{array}{c}0.97938 \\
1\end{array}$ \\
\hline 5 & $\begin{array}{c}0.07 \\
7\end{array}$ & $\begin{array}{c}0.08 \\
4\end{array}$ & $\begin{array}{c}0.11 \\
1\end{array}$ & $\begin{array}{c}0.13 \\
0\end{array}$ & $\begin{array}{c}0.15 \\
0\end{array}$ & $\begin{array}{c}0.16 \\
7\end{array}$ & $\begin{array}{c}0.16 \\
7\end{array}$ & $\begin{array}{c}0.18 \\
2\end{array}$ & $\begin{array}{c}0.22 \\
2\end{array}$ & $\begin{array}{c}0.72164 \\
9\end{array}$ & 0.87628866 & $\begin{array}{c}0.97938 \\
1\end{array}$ \\
\hline 10 & $\begin{array}{c}0.08 \\
3\end{array}$ & $\begin{array}{c}0.08 \\
7\end{array}$ & $\begin{array}{c}0.11 \\
1\end{array}$ & $\begin{array}{c}0.08 \\
6\end{array}$ & $\begin{array}{c}0.09 \\
4\end{array}$ & $\begin{array}{c}0.10 \\
0\end{array}$ & $\begin{array}{c}0.10 \\
0\end{array}$ & $\begin{array}{c}0.10 \\
8\end{array}$ & $\begin{array}{c}0.11 \\
8\end{array}$ & $\begin{array}{c}0.65979 \\
4\end{array}$ & $\begin{array}{c}0.82474226 \\
8\end{array}$ & $\begin{array}{c}0.96907 \\
2\end{array}$ \\
\hline 15 & $\begin{array}{c}0.25 \\
0\end{array}$ & $\begin{array}{c}0.33 \\
3\end{array}$ & $\begin{array}{c}1.00 \\
0\end{array}$ & $\begin{array}{c}0.50 \\
0\end{array}$ & $\begin{array}{c}0.66 \\
7\end{array}$ & $\begin{array}{c}1.00 \\
0\end{array}$ & $\begin{array}{c}0.33 \\
3\end{array}$ & $\begin{array}{c}0.50 \\
0\end{array}$ & $\begin{array}{c}1.00 \\
0\end{array}$ & $\begin{array}{c}0.72164 \\
9\end{array}$ & $\begin{array}{c}0.86597938 \\
1\end{array}$ & $\begin{array}{c}0.96907 \\
2\end{array}$ \\
\hline 20 & $\begin{array}{c}0.10 \\
0\end{array}$ & $\begin{array}{c}0.11 \\
2\end{array}$ & $\begin{array}{c}0.14 \\
3\end{array}$ & $\begin{array}{c}0.42 \\
9\end{array}$ & $\begin{array}{c}0.60 \\
0\end{array}$ & $\begin{array}{c}0.75 \\
0\end{array}$ & $\begin{array}{c}0.33 \\
3\end{array}$ & $\begin{array}{c}0.22 \\
2\end{array}$ & $\begin{array}{c}1.00 \\
0\end{array}$ & $\begin{array}{c}0.74226 \\
8\end{array}$ & 0.87628866 & 1 \\
\hline
\end{tabular}

\section{Step 3: Develop the Weighted Normalized Decision Matrix}

Each criterion has given different weights according to its importance. Using these weights of every criterion, the weighted normalized decision matrix can be calculated by using the following formula:

$\tilde{v}_{i j}=\tilde{r}_{i j} \cdot \widetilde{w}_{i j}$

where, $\widetilde{w}_{i j}$ represents the weight of criterion $c_{j}$. Table 11 shows the weighted normalized decision matrix.

Table 11. Weighted normalized fuzzy decision matrix.

\begin{tabular}{|c|c|c|c|c|c|c|c|c|c|c|c|c|}
\hline Weights & 1 & 1 & 3 & 1 & 3 & 5 & 1 & 3 & 5 & 5 & 7 & 9 \\
\hline $\begin{array}{c}\text { Bus } \\
\text { Number }\end{array}$ & \multicolumn{3}{|c|}{ Loss } & \multicolumn{3}{|c|}{ Real Power } & \multicolumn{3}{|c|}{ Reactive Power } & \multicolumn{3}{|c|}{ Voltage } \\
\hline $\mathbf{0}$ & $\begin{array}{c}0.08 \\
3\end{array}$ & $\begin{array}{c}0.09 \\
5\end{array}$ & 0.3 & $\begin{array}{c}0.10 \\
7\end{array}$ & $\begin{array}{c}0.34 \\
6\end{array}$ & 0.625 & $\begin{array}{c}0.13 \\
3\end{array}$ & $\begin{array}{c}0.46 \\
2\end{array}$ & $\begin{array}{c}0.90 \\
9\end{array}$ & $\begin{array}{c}3.60824 \\
7\end{array}$ & $\begin{array}{c}6.1340206 \\
19\end{array}$ & $\begin{array}{c}8.81443 \\
3\end{array}$ \\
\hline 5 & $\begin{array}{c}0.07 \\
7\end{array}$ & $\begin{array}{c}0.08 \\
4\end{array}$ & $\begin{array}{c}0.33333 \\
3\end{array}$ & $\begin{array}{c}0.13 \\
0\end{array}$ & $\begin{array}{c}0.45 \\
0\end{array}$ & $\begin{array}{c}0.83333 \\
3\end{array}$ & $\begin{array}{c}0.16 \\
7\end{array}$ & $\begin{array}{c}0.54 \\
5\end{array}$ & $\begin{array}{c}1.11 \\
1\end{array}$ & $\begin{array}{c}3.60824 \\
7\end{array}$ & $\begin{array}{c}6.1340206 \\
19\end{array}$ & $\begin{array}{c}8.81443 \\
3\end{array}$ \\
\hline 10 & $\begin{array}{c}0.08 \\
3\end{array}$ & $\begin{array}{c}0.08 \\
7\end{array}$ & $\begin{array}{c}0.33333 \\
3\end{array}$ & $\begin{array}{c}0.08 \\
6\end{array}$ & $\begin{array}{c}0.28 \\
1\end{array}$ & 0.5 & $\begin{array}{c}0.10 \\
0\end{array}$ & $\begin{array}{c}0.32 \\
4\end{array}$ & $\begin{array}{c}0.58 \\
8\end{array}$ & $\begin{array}{c}3.29896 \\
9\end{array}$ & $\begin{array}{c}5.7731958 \\
76\end{array}$ & $\begin{array}{c}8.72164 \\
9\end{array}$ \\
\hline 15 & $\begin{array}{c}0.25 \\
0\end{array}$ & $\begin{array}{c}0.33 \\
3\end{array}$ & 3 & $\begin{array}{c}0.50 \\
0\end{array}$ & $\begin{array}{c}2.00 \\
0\end{array}$ & 5 & $\begin{array}{c}0.33 \\
3\end{array}$ & $\begin{array}{c}1.50 \\
0\end{array}$ & $\begin{array}{c}5.00 \\
0\end{array}$ & $\begin{array}{c}3.60824 \\
7\end{array}$ & $\begin{array}{c}6.0618556 \\
7\end{array}$ & $\begin{array}{c}8.72164 \\
9\end{array}$ \\
\hline 20 & $\begin{array}{c}0.10 \\
0\end{array}$ & $\begin{array}{c}0.11 \\
2\end{array}$ & $\begin{array}{c}0.42857 \\
1\end{array}$ & $\begin{array}{c}0.42 \\
9\end{array}$ & $\begin{array}{c}1.80 \\
0\end{array}$ & 3.75 & $\begin{array}{c}0.33 \\
3\end{array}$ & $\begin{array}{c}0.66 \\
7\end{array}$ & $\begin{array}{c}5.00 \\
0\end{array}$ & 3.71134 & $\begin{array}{c}6.1340206 \\
19\end{array}$ & 9 \\
\hline
\end{tabular}

Step 4: Computation of Fuzzy best Ideal Solution (FBIS, A*) and Fuzzy Worst Ideal Solution $\left(F W I S, A^{-}\right)$

The FBIS and FWIS can be computed as given below:

$$
\begin{gathered}
A^{*}=\left\{\tilde{v}_{1}^{*}, \tilde{v}_{2}^{*}, \ldots, \tilde{v}_{n}^{*}\right\}=\left\{\left(\max _{j} v_{i j} \mid i \in P\right),\left(\min _{j} v_{i j} \mid i \in Q\right)\right\} \\
A^{-}=\left\{\tilde{v}_{1}^{-}, \tilde{v}_{2}^{-}, \ldots, \tilde{v}_{n}^{-}\right\}=\left\{\left(\min _{j} v_{i j} \mid i \in P\right),\left(\max _{j} v_{i j} \mid i \in Q\right)\right\}
\end{gathered}
$$

where, $\tilde{v}_{i}^{*}$ and $\tilde{v}_{i}^{-}$is the maximum and minimum value of $\mathrm{i}^{\text {th }}$ alternatives. $\mathrm{P}$ and $\mathrm{Q}$ represent the best and worst ideal solutions, respectively. The best and worst-ideal solutions are shown in Table 12 . 
Table 12. Best and worst-ideal solutions.

\begin{tabular}{|c|c|c|}
\hline Criteria & Best- ideal $\left(\boldsymbol{A}^{*}\right)$ & Worst- ideal $\left(\boldsymbol{A}^{-}\right)$ \\
\hline Loss & $(0.077,0.084,0.030)$ & $(0.250,0.333,3.000)$ \\
\hline Real Power & $(0.086,0.281,0.500)$ & $(0.500,2.000,5.000)$ \\
\hline Reactive Power & $(0.100,0.324,0.588)$ & $(0.333,1.500,0.500)$ \\
\hline Voltage & $(3.711,6.134,9.000)$ & $(3.299,5.773,8.722)$ \\
\hline
\end{tabular}

\section{Step 5: Distance Calculation}

The distance, FBIS, and FWIS have been computed below:

$S_{i}^{*}=\sum_{j=1}^{n} d\left(\tilde{v}_{i j}, \tilde{v}_{j}^{*}\right) \quad i=1,2, \ldots, m$

$S_{i}^{-}=\sum_{j=1}^{n} d\left(\tilde{v}_{i j}, \tilde{v}_{j}^{-}\right) \quad i=1,2, \ldots, m$

' $\mathrm{d}$ ' represents the distance between two triangular fuzzy numbers, assuming $\left(a_{1}, b_{1}, c_{1}\right) \&$ $\left(a_{2}, b_{2}, c_{2}\right)$, by using the formula given below:

$d_{v}\left(\widetilde{M}_{1}, \widetilde{M}_{2}\right)=\sqrt{\frac{1}{3}\left[\left(a_{1}-a_{2}\right)^{2}+\left(b_{1}-b_{2}\right)^{2}+\left(c_{1}-c_{2}\right)^{2}\right]}$

Note that $d\left(\tilde{v}_{i j}, \tilde{v}_{j}^{*}\right)$ and $d\left(\tilde{v}_{i j}, \tilde{v}_{j}^{-}\right)$are crisp numbers.

Table $13 \& 14$ shows the distance from best and worst- ideal solutions.

Table 13. Distance from FBIS.

\begin{tabular}{|c|c|c|c|c|c|}
\hline Bus Number & \multicolumn{4}{|c|}{ Distance from FBIS } & $S_{i}^{*}$ \\
\hline $\mathbf{0}$ & 0.007 & 0.082 & 0.202 & 0.123 & 0.415 \\
\hline 5 & 0.019 & 0.217 & 0.330 & 0.123 & 0.689 \\
\hline 10 & 0.020 & 0.000 & 0.000 & 0.355 & 0.375 \\
\hline 15 & 1.569 & 2.791 & 2.639 & 0.176 & 7.176 \\
\hline 20 & 0.077 & 2.081 & 2.558 & 0.000 & 4.716 \\
\hline
\end{tabular}

Table 14. Distance from FWIS.

\begin{tabular}{|c|c|c|c|c|c|}
\hline Bus Number & \multicolumn{3}{|c|}{ Distance from FWIS } & $\boldsymbol{S}_{\boldsymbol{i}}^{-}$ \\
\hline $\mathbf{0}$ & 1.568 & 2.710 & 2.440 & 0.280 & 6.997 \\
\hline $\mathbf{5}$ & 1.550 & 2.576 & 2.314 & 0.280 & 6.719 \\
\hline $\mathbf{1 0}$ & 1.549 & 2.791 & 2.639 & 0.000 & 6.980 \\
\hline $\mathbf{1 5}$ & 0.000 & 0.000 & 0.000 & 0.244 & 0.244 \\
\hline $\mathbf{2 0}$ & 1.493 & 0.732 & 0.481 & 0.355 & 3.061 \\
\hline
\end{tabular}

\section{Step 6: Compute the Coefficient of Closeness and Alternatives Rank}

The coefficient of closeness for every alternative using the formula given below:

$$
C C_{i}=\frac{S_{i}^{-}}{S_{i}^{+}+S_{i}^{-}}
$$

The optimal decision is close to FBIS and far to FWIS. Table 15 contains the computed value of $C C_{i}$ and the preference order about different Bus Numbers. Figure 4 presents the closeness coefficient of each alternative. 
Table 15. Closeness coefficient.

\begin{tabular}{|c|c|c|}
\hline Bus Number & $\boldsymbol{C C}_{\boldsymbol{i}}$ & Rank \\
\hline $\mathbf{0}$ & 0.944052 & 2 \\
\hline $\mathbf{5}$ & 0.906978 & 3 \\
\hline $\mathbf{1 0}$ & 0.949078 & 1 \\
\hline $\mathbf{1 5}$ & 0.032917 & 5 \\
\hline $\mathbf{2 0}$ & 0.393559 & 4 \\
\hline
\end{tabular}

According to the results given in Table 15, the closeness coefficient value 0.949078 for bus 10 is the highest among the others, thus the DG should be placed at bus 10 followed by bus $0,5,20$, and 15 having the closest coefficient values as $0.944052,0.906978,0.393559$, and 0.032917 .

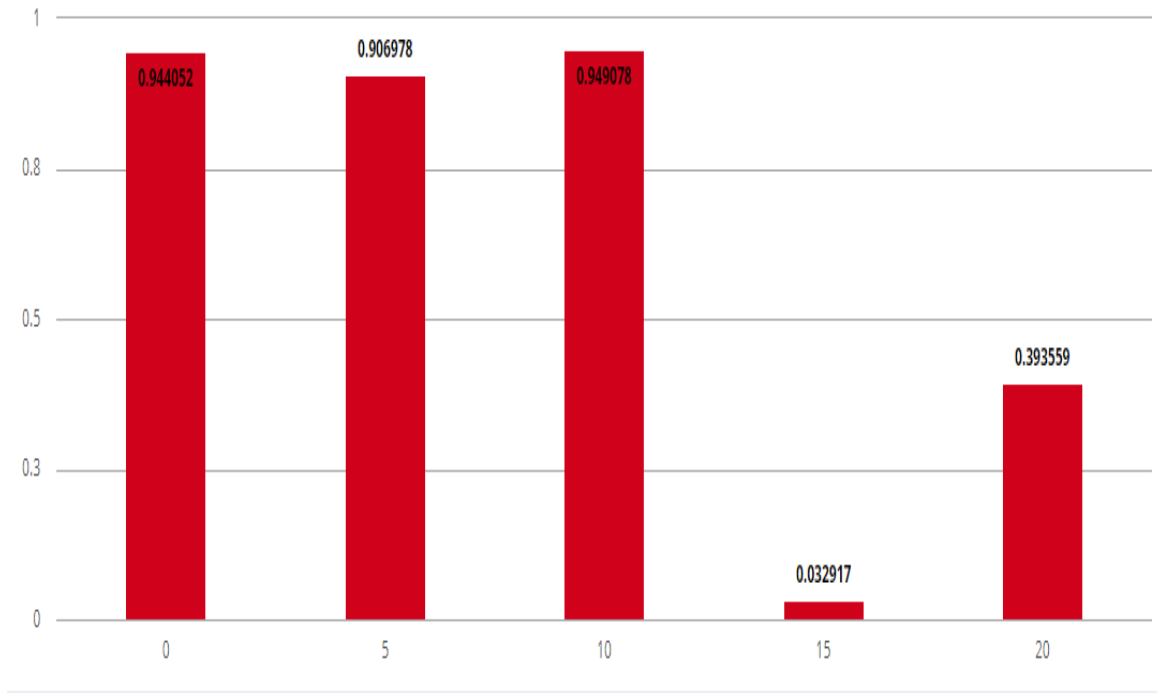

Figure 4. Closeness coefficient graph using fuzzy TOPSIS.

\section{Conclusions and Future Implications}

The current proposal is based on the determination of the best location for the placement of a DG unit in the IEEE 20 bus system. For the smart grids, DG placement has always been an important concern for decision-makers as they always wish to minimize the losses in power transmission and distribution. But in a real scenario, many conflicting attributes need attention to ease the selection process. Here a multi-criteria decision-making technique named TOPSIS and the extension of technique with fuzzy numbers have been employed. According to the TOPSIS, the optimal location is on bus 15 which is closer to the customer end and the results obtained using Fuzzy TOPSIS, the optimal location is bus 10 which is the middle location of the system.

By utilizing the Fuzzy TOPSIS, the optimal placements of DG units are in line with the results obtained by notable contributors in literature (Campoccia et al., 2008; Muthukumar and Jayalalitha, 2016) which claims that the least losses are experienced at the middle node. In the future, the work can be extended to employ other MCDM techniques like AHP, ISM, TISM, EDAS can be applied and tested for different IEEE bus systems. Different functional representations of fuzzy numbers 
can be utilized to understand the change in the decision for optimal placement of DG. Also, the comparison can be done for preference based on different geographical regions.

\section{Conflict of Interest}

The authors confirm that there is no conflict of interest to declare for this publication.

\section{Acknowledgments}

The authors are thankful to the anonymous referees of the journal for their extremely useful suggestions to improve the quality of the article.

\section{References}

Barker, P.P., \& De Mello, R.W. (2000, July). Determining the impact of distributed generation on power systems. i. radial distribution systems. In 2000 Power Engineering Society Summer Meeting (Cat. No. 00CH37134), (Vol. 3, pp. 1645-1656). IEEE. Seattle, WA, USA. doi:10.1109/PESS.2000.868775.

Campoccia, A., Riva Sanseverino, E., \& Zizzo, G. (2008). Optimal sizing and siting of distributed energy resources considering public and private incentive policies. In: Nguyen, N.T., Borzemski, L., Grzech, A., Ali, M. (eds). IEA/AIE 2008. Lecture Notes in Computer Science, vol 5027. Springer. Berlin, Heidelberg. https://doi.org/10.1007/978-3-540-69052-8_60

Chaube, S., \& Singh, S.B. (2016). Fuzzy reliability theory based on membership function. International Journal of Mathematical, Engineering and Management Sciences, 1(1), 34-40. doi: 10.33889/IJMEMS.2016.1.1-004.

Chiradeja, P., \& Ramakumar, R. (2004). An approach to quantify the technical benefits of distributed generation. IEEE Transactions on Energy Conversion, 19(4), 764-773. doi: 10.1109/TEC.2004.827704.

Dugan, R.C., \& Mcdermott, T.E. (2002). Distributed generation. IEEE Industry Applications Magazine, 8(2), 19-25. doi: 10.1109/2943.985677.

Dugan, R.C., McDermott, T.E., \& Ball, G.J. (2001). Planning for distributed generation. IEEE Industry Applications Magazine, 7(2), 80-88. doi: 10.1109/2943.911193.

El-Khattam, W., \& Salama, M.M.A. (2004). Distributed generation technologies, definitions and benefits. Electric Power Systems Research, 71(2), 119-128. https://doi.org/10.1016/j.epsr.2004.01.006.

Guerrero, J.M., Blaabjerg, F., Zhelev, T., Hemmes, K., Monmasson, E., Jemei, S., Comech, M.P., Granadino, R., \& Frau, J.I. (2010). Distributed generation: toward a new energy paradigm. IEEE Industrial Electronics Magazine, 4(1), 52-64. doi: 10.1109/MIE.2010.935862.

Gupta, N., Agarwal, M., Garg, P., \& Bansal, M. (2021). Revenue optimization modeling for renewable energy resource mix for sustainable development. Journal of Revenue and Pricing Management, 20(2), $108-115$

Hwang, C.L., \& Yoon, K. (1981). Multiple attribute decision making: methods and applications a state-ofthe-art survey. Springer-Verlag Berlin Heidelberg, New York.

Li, D.F. (2010). TOPSIS-based nonlinear-programming methodology for multiattribute decision making with interval-valued intuitionistic fuzzy sets. IEEE Transactions on Fuzzy Systems, 18(2), 299-311. doi: 10.1109/TFUZZ.2010.2041009.

Linares, P., \& Romero, C. (2000). A multiple criteria decision-making approach for electricity planning in Spain: economic versus environmental objectives. Journal of the Operational Research Society, 51(6), 736-743. https://doi.org/10.1057/palgrave.jors.2600944. 
Malik, M.Z., Kumar, M., Soomro, A.M., Baloch, M.H., Gul, M., Farhan, M., \& Kaloi, G.S. (2020). Strategic planning of renewable distributed generation in radial distribution system using advanced MOPSO method. Energy Reports, 6, 2872-2886. https://doi.org/10.1016/j.egyr.2020.10.002.

Mills, D., Vlacic, L., \& Lowe, I. (1996). Improving electricity planning-use of a multicriteria decisionmaking model. International Transactions in Operational Research,3(3-4), 293-304. https://doi.org/10.1111/j.1475-3995.1996.tb00054.x.

Muthukumar, K., \& Jayalalitha, S. (2016). Optimal placement and sizing of distributed generators and shunt capacitors for power loss minimisation in radial distribution networks using hybrid heuristic search optimisation technique. International Journal of Electrical Power \& Energy Systems, 78, 299-319. https://doi.org/10.1016/j.ijepes.2015.11.019.

Pepermans, G., Driesen, J., Haeseldonckx, D., Belmans, R., \& D’haeseleer, W. (2005). Distributed generation: definition, benefits and issues. Energy Policy, 33(6), 787-798. https://doi.org/10.1016/j.enpol.2003.10.004.

Pohekar, S.D., \& Ramachandran, M. (2004). Application of multi-criteria decision making to sustainable energy planning-a review. Renewable and Sustainable Energy Reviews, 8(4), 365-381. https://doi.org/10.1016/j.rser.2003.12.007.

Ramesh, L., Ravindiran, S., Chowdhury, S.P., Chowdhury, S., Song, Y.H., \& Goswami, P.K. (2007, September). Distribution system loss minimisation and planning using cymdist. In 2007 42nd International Universities Power Engineering Conference, (pp. 316-321). IEEE. Brighton, UK. doi: 10.1109/UPEC.2007.4468967.

Razavi, S.E., Rahimi, E., Javadi, M.S., Nezhad, A.E., Lotfi, M., Shafie-khah, M., \& Catalão, J.P.S. (2019). Impact of distributed generation on protection and voltage regulation of distribution systems: a review. Renewable and Sustainable Energy Reviews, 105, 157-167. doi: 10.1016/j.rser.2019.01.050.

Ren, J., \& Dong, L. (2018). Evaluation of electricity supply sustainability and security: multi-criteria decision analysis approach. Journal of Cleaner Production, 172, 438-453. doi: 10.1016/j.jclepro.2017.10.167.

Saikia, R., Garg, H., \& Dutta, P. (2020). Fuzzy multi-criteria decision making algorithm under intuitionistic hesitant fuzzy set with novel distance measure. International Journal of Mathematical, Engineering and Management Sciences, 5(3), 473-487. doi:10.33889/ijmems.2020.5.3.039.

Šarić, M., Hivziefendić, J., \& Konjić, T. (2017, October). Distributed generation allocation using fuzzy multicriteria decision making algorithm. In 2017 International Conference on Smart Systems and Technologies (SST), (pp. 203-208). IEEE. Osijek, Croatia. doi: 10.1109/SST.2017.8188696. 